\title{
SELF-MONITORING OF GLUCOSE WITH A NON-INVASIVE METHOD USING NEAR INFRARED SENSOR
}

\author{
Rinda N Hidayati ${ }^{1}$, Nur H Ahniar ${ }^{1)}$, Gita R Lestari ${ }^{1)}$, Atika Hendryani ${ }^{1)}$, and Faris Al \\ Hakim ${ }^{1}$, \\ ${ }^{1}$ Jurusan Teknik Elektromedik, Poltekkes Kemenkes Jakarta II, Jln. Hang Jebat III, Jakarta \\ Selatan \\ E-mail: tfrinda@gmail.com
}

Submitted: $16^{\text {th }}$ October 2020; Accepted: $24^{\text {th }}$ November 2020

https://doi.org/10.36525/sanitas.2020.10

\begin{abstract}
Diabetes mellitus or commonly called diabetes is a worldwide epidemic caused by chronic hyperglycemia. Simplify the glucose monitoring and easy to use is an essential part of diabetes management. Currently, the use of blood glucose meters conventional in clinical practice needs sufficient reliability. Therefore, self-monitoring of blood glucose with a non-invasive method was presented. A non-invasive blood glucose monitoring device was initially for information on glucose level measurements. A non-invasive method to determine the level of glucose by applying the physical properties of the absorption of the laser sensor that can produce a voltage change at various glucose levels. In this paper, a glucose monitoring module was fabricated with dimensions of $25 \times 27 \times 15 \mathrm{~cm}$ which has a minimum system, sensor, and LCD as a display of glucose levels. A minimum system to control the output of data digital value using microcontroller Android nano v.3. Experimentally, testing this module is by comparing the glucose monitoring modules that have been made with a gold standard. The result showed that non-invasive glucose monitoring is the potential for glucose level measurement a sensitivity, resolution, and accuracy of $0.86 \mathrm{mg} / \mathrm{dL}, 0.01 \mathrm{mg} / \mathrm{dL}$, and $98.40 \%$, respectively. The purposed module of glucose level monitoring offered simple testing for the rapid measurement of glucose levels.
\end{abstract}

Keywords: Diabetes mellitus, blood glucose, non-invasive, sensor, near infrared

This is an open access journal, and articles are distributed under the terms of the Creative Commons Attribution-Non Commercial-Share Alike 4.0 License, which allows others to remix, tweak, and build upon the work non-commercially, as long as appropriate credit is given and the new creations are licensed under the identical terms. (02020 Sanitas

\section{INTRODUCTION}

Diabetes Mellitus (DM) or ordinarily referred to as diabetes is known as the quiet executioner since it is regularly not understood by individuals and when found to have intricacies. Diabetes is a chronic metabolic disorder because the pancreas doesn't create enough insulin or the body can't utilize the insulin that is delivered successfully. Basic Health 
Research (Riskesdas) in 2007 and 2013 found that the proportion of people with diabetes mellitus in 2013 nearly doubled compared to 2007 (1).

Diabetes mellitus is one of the leading causes of death, disability, and economic loss throughout the world (2)(3). WHO estimates there are 171 million people worldwide with diabetes mellitus in 2000 and estimates that 366 million people will suffer from diabetes mellitus by 2030 (2)(4). The International Diabetes Federation estimates that another 314 million people have glucose levels above normal levels, and that number will increase to 472 million by 2030 (5). In the United States, for instance, as much as $6.3 \%$ of the populace experienced diabetes mellitus in 2002 (6). The US Centers for Disease Control and Prevention assesses that 13 million individuals in the United States have analyzed diabetes mellitus and an extra 5.2 million have the illness however have not yet been analyzed (7). In 2015, Indonesia was positioned seventh in the world for the most elevated pervasiveness of diabetes on the planet alongside China, India, the United States, Brazil, Russia, and Mexico with an expected 10 million individuals with diabetes. The percentage of deaths due to diabetes in Indonesia is the second-highest after Sri Lanka. The prevalence of diabetes has an upward trend of $5.7 \%$ in 2017 to $6.9 \%$ in 2013 (8).

In prevention efforts, diabetics must do regular health checks, avoid cigarette smoke, and don't smoke, be diligent in physical activity, maintain a balanced diet, get adequate rest, and manage stress correctly. Health checks in the form of checking blood glucose levels can be done independently at home or visit the nearest health facility. The diagnosis of diabetes depends on monitoring blood glucose. Monitoring of blood glucose levels needs to be done at least 4 times a day to get blood samples or about 1800 times per year and requires a testing time of about 2 hours. There are many reports of infections caused by injections. Infection occurs because people with DM cannot produce insulin in the body. As an alternative, approaches to measuring glucose concentrations in body fluids including urine, saliva, and tear fluid, have great potential for noninvasive diagnosis (diagnosis of disease without injuring the patient's body) of diabetes.

Currently, testing for blood glucose levels can only be done on an invasive basis. A person with diabetes must perform a test in the laboratory by taking a blood sample. Besides, currently there is also a blood glucose level measuring device that can be used independently 
at home. However, the patient still has to bleed the sample to be tested. In testing using a blood sample, the patient is exposed to the risk of developing a hematoma or bruise, a condition in which blood pools outside the blood vessels. This condition is caused by damaged blood vessels.

A few improvements in research regarding blood glucose detection have been developed. Zahra Khairunnisa (2014), has made a non-invasive blood glucose level measuring device using a photodiode sensor. In his research, a photodiode was applied as a light sensor on blood glucose levels measuring devices by utilizing the optoelectric phenomenon. Photodiodes are proven to be more effective than using photoresistors because the absorption of light is greater (9). Research conducted by Enze Zhang is the design and human trials of microwave noninvasive blood glucose detection sensors. This research using a split-ring resonator as a non-invasive blood glucose sensor. The result of this research is the most extreme mistake acquired which seemed 10 minutes after eating starches, is about 0.96 $\mathrm{mmol} / \mathrm{L}$ (10). Research of blood glucose was made by Gayathri, B. in 2017 utilizing the dissipating property of glucose particles and the rule of photoplethysmography. The handling of information utilizing MSP430G2553 microcontroller in the incorporated advancement climate (IDE) of Code Composer Studio (CCS). The outcome is a connection between blood glucose concentration and photoplethysmograph is inferred (11).

In concept, the light is absorbed by the body by utilizing the phenomenon of scattering and absorption. This phenomenon can be investigating the blood glucose level with a noninvasive method. According to this theory, research is carried out using Near-Infrared at a wavelength of $940 \mathrm{~nm}$ as a sensor. The sensors are put precisely inverse to one another so that photodiode can identify the light following embeddings a finger (12). In 2020, A smart glucose monitoring system for diabetic patients was developed. The technology that has been developed is based on information data of diabetic patients which combine with the Internet of Things. To establish secure data of diabetic patients was designed a wireless connection with the smartphone (13).

Based on these issues, the purpose of this study was to develop the self-monitoring of blood glucose with a non-invasive method. This study focused on the use of photodiode sensors as sensors that can be used to detect glucose levels in the body. Through this research, 
it is expected to contribute to the detection of glucose levels independently to facilitate the research process and the detection of diabetes mellitus.

\section{METHODOLOGY}

\section{A. Experimental Set Up}

This study utilized five typical subjects with the measures the ages went somewhere in the range of 22 and 25 years of age and the weight is between 60 to $70 \mathrm{~kg}$. The subjects were arbitrarily examined and the information assortment is rehashed 5 times. This study was using an easy touch blood measuring device (Easy Touch, PT. Tekno Medicalogi, Indonesia), is used as a comparison tool for the modules made. The photodiode used is BPW 34. The oscilloscope is used as an analog circuit testing tool. In this study, after the design was finished, the signal conditioning circuit was estimated utilizing an oscilloscope to see the frequency produced. As a comparison of the final results in this module, we compare with Easy Touch blood measurement. Next, we measured the results of blood glucose in humans.

\section{B. The Diagram Block}

In this research, it uses two sensors namely LED as a transmitter and photodiode as a receiver. This sensor reads the potential differences that exist in our body as a large indicator of the value of blood glucose in our bodies. The potential difference read by the sensor will be strengthened by the signal conditioning circuit. Furthermore, it is forwarded to Arduino as a signal processor, will convert analog signals in the form of voltage to digital signals so that the results of blood glucose levels can be displayed on the LCD screen.

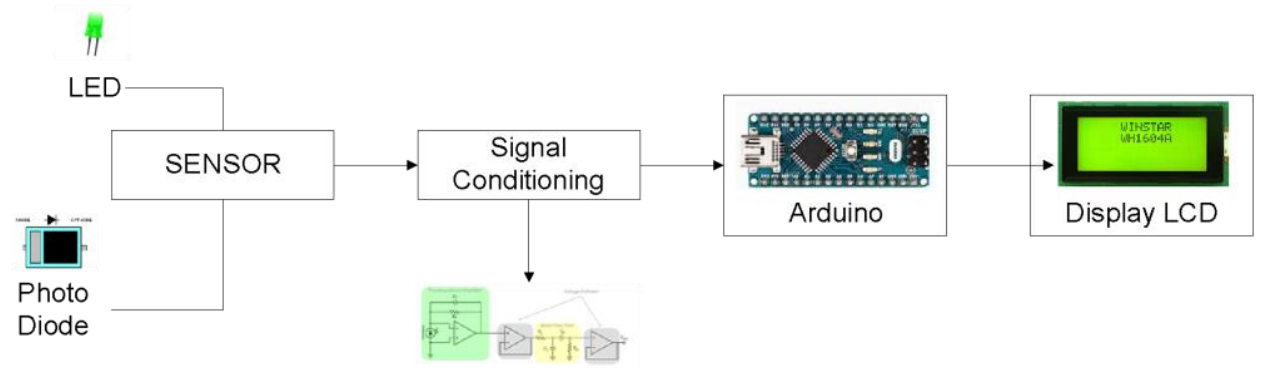

Figure 1. The diagram block of blood glucose measurement 


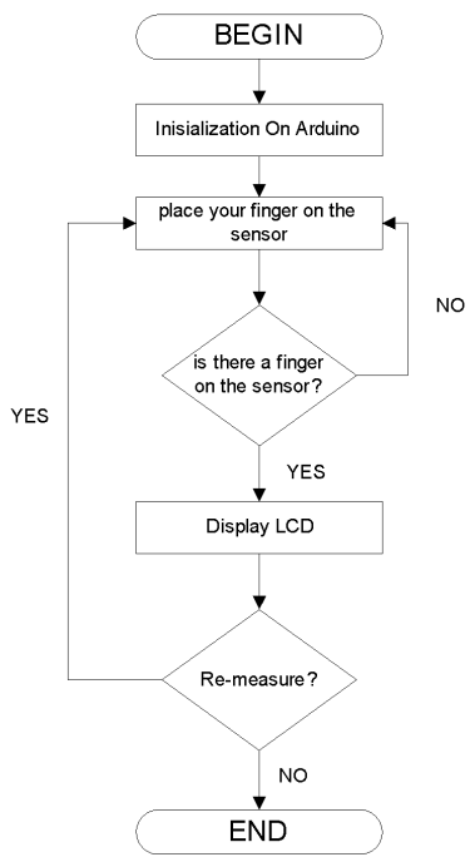

Figure 2. Flowchart of the Arduino Program

The Arduino program was assembled dependent on the flowchart as appeared in Figure. 2. After the Arduino introduction, the module will be utilized. Furthermore, the program will analyze whether there are fingers placed on the sensor or not, if there are fingers placed on the sensor, the program will read and display the measurement results on the LCD.

\section{The Analog Circuit}

The important part of this development is the analog circuit (photodiode sensor, high pass filter, and low pass filter) which will be described in Figure 3. High pass filter and low pass filter are a series of signal conditioning that is used as a filter to process signals from sensors. Hence it will be ready for digital processing using Arduino. The photodiode sensor used will be provided with a resistor of $39 \mathrm{k} \Omega$ as a guard so that the photodiode is not hot and damaged due to excess current. The voltage source for this VCC circuit uses $+5 \mathrm{~V}$ from Arduino. Furthermore, the output of this circuit goes to the filter circuit.

A high pass filter is a filter that serves to filter the frequency signal below the cut-off frequency and pass frequencies that are above the cut-off value. Determination of the component values in the high pass filter above can be determined by first determining the 
cut-off frequency needed, in this design, the required high pass filter has a cut-off frequency of $0.5 \mathrm{~Hz}$. With a predetermined cut-off frequency limit, the values of resistors and capacitors to meet the results of that frequency. This circuit uses a $40 \mathrm{~Hz}$ frequency with a $220 \mathrm{nF}$ capacitor, so the R-value used is $3 \mathrm{M} \Omega$. The low pass filter is a type of filter that will filter frequencies above the cut-off frequency and will pass frequencies below the cut-off frequency. Low pass filter is a type of filter that will filter frequencies above the cut-off frequency and will pass frequencies below the cut-off frequency. From predetermined frequency values, capacitor and resistor values must be sought to meet the desired cut-off frequency value. This circuit uses a $40 \mathrm{~Hz}$ frequency with a $100 \mathrm{nF}$ capacitor, so the R-value used is $39 \mathrm{k} \Omega$.

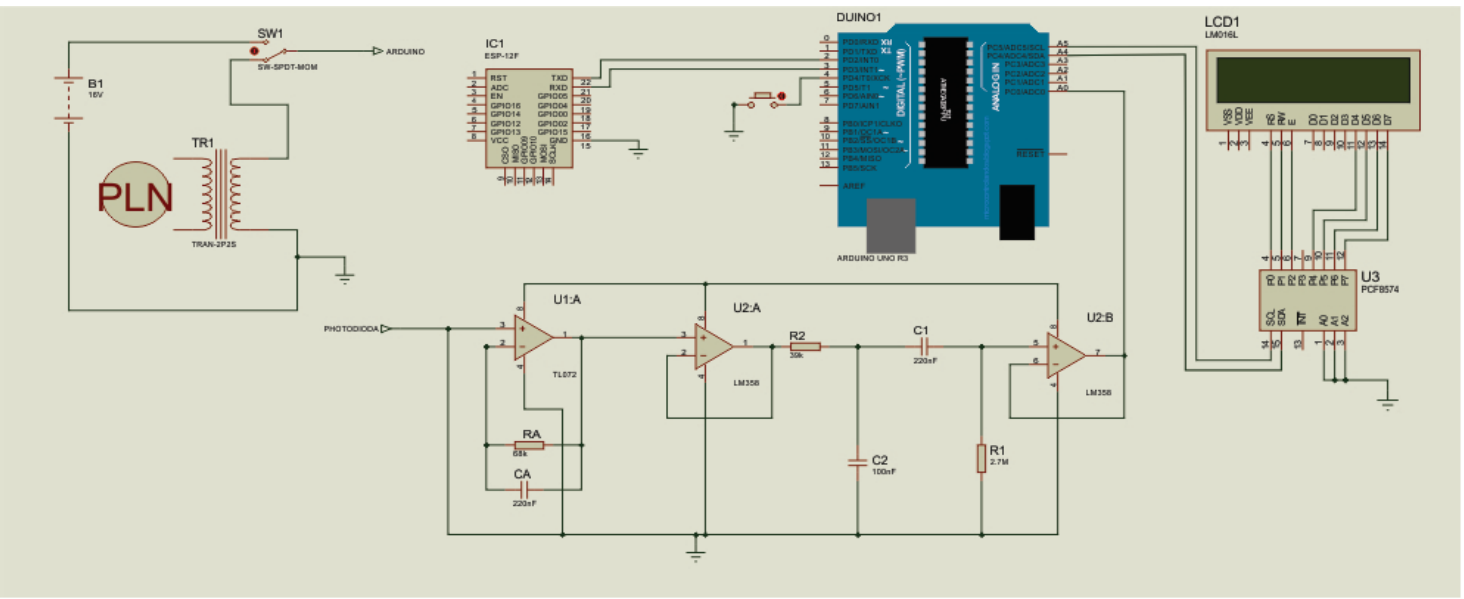

Figure 3. The part of analog circuit (photodiode sensor, high pass filter, and low pass filter)

\section{RESULT AND DISCUSSION}

In this study, the blood glucose module has been compared using a blood glucose measurement (Easy Touch). The result shows there is no significant difference between two measurements. The discussion includes the blood glucose non-invasive design, photodiode sensor testing, blood glucose measurement, and performance of the blood glucose module.

\section{1) Blood Glucose non-invasive Design}

The design of the blood glucose non-invasive module was shown in Figure 4. The analog part of this instrument uses a probe that is connected to the tool to function as a place to place the patient's finger. Inside the probe, there is Superbright Green LED as a transmitter and a 
photodiode sensor (BPW34) as a receiver. This sensor reads the potential difference in the patient's finger as an indicator of the value of blood glucose in the patient's body. The potential difference read by the sensor will be amplified by a signal conditioning circuit, which consists of a series of LPF and HPF filters. The filter circuit uses the JRC4558 and LM358 Op-Amp ICs. Then forwarded to the Arduino Nano as a microcontroller which functions as a data processor when initializing the LCD and processing the measured analog signal data, the ADC on the Arduino Nano will convert the analog signal in the form of a voltage into a digital signal.

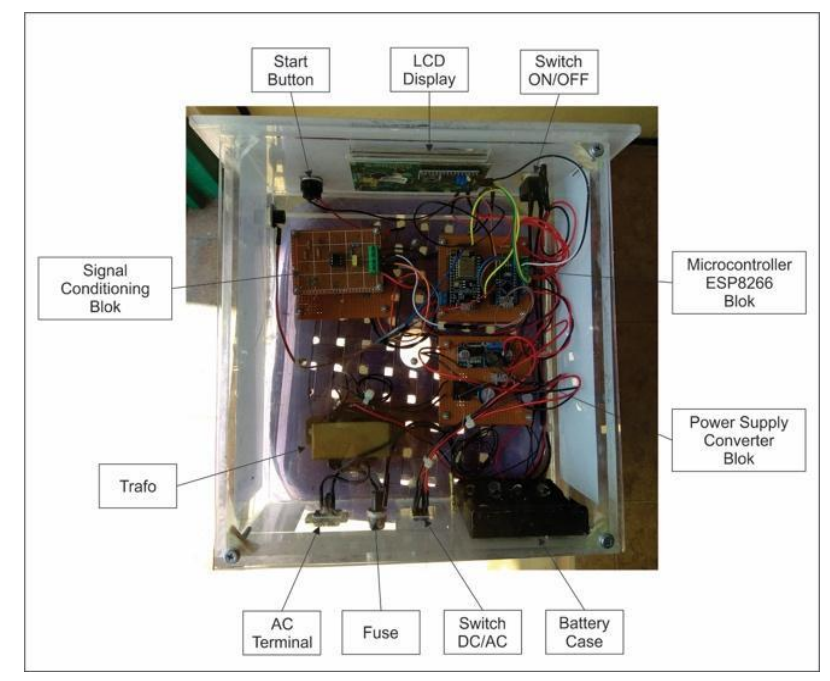

Figure 4. Hardware design of blood glucose module

\section{2) Photodioda sensor testing}

In the photodiode sensor test, done by placing the probe on the patient's fingertip and comparing it with a multimeter. The LCD will display the output voltage from the photodiode sensor. The test uses an AVO meter, the value of the voltage generated by the photodiode sensor circuit is $5.39 \mathrm{~V}$ in the fingerless condition and reduced by $0.03 \mathrm{~V}$ the finger-free condition. The VCC source of the photodiode sensor from Arduino is $4.98 \mathrm{~V}$.

\section{3) The measurement of blood glucose}

In this study, we measured 5 volunteers, ranging in age from 22-25 years. We took 2 measurements with the conditions before eating and at random times, each measurement was 
carried out 3 times the data collection. As a comparison, we also measured the volunteers with an invasive measuring blood glucose level (easy touch). The result can be seen on Figure 6 and Figure 7.

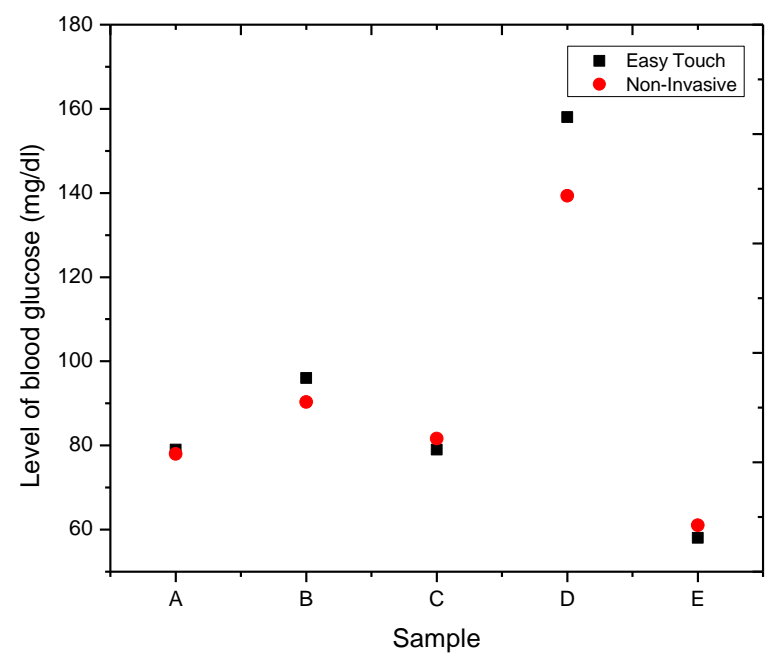

Figure 6. The result of blood glucose measurement at before eating condition

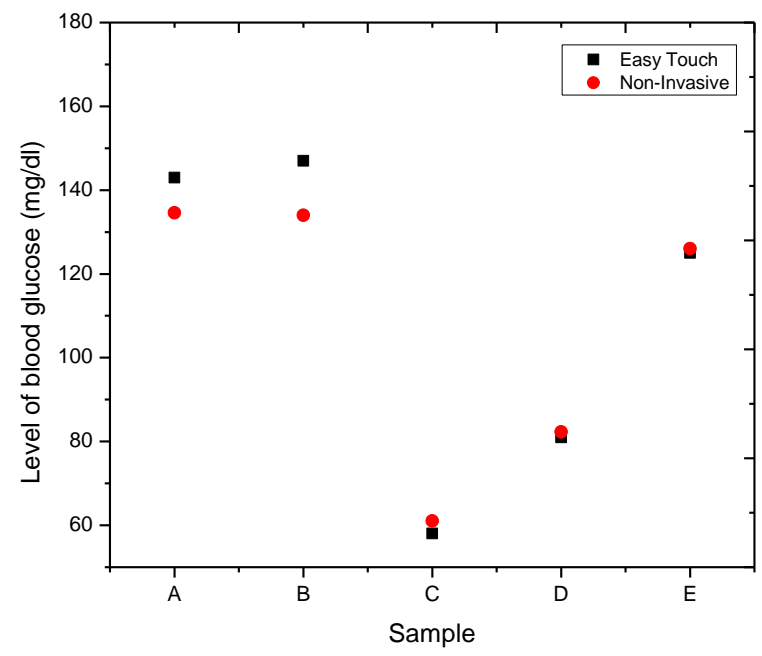

Figure 7. The result of blood glucose measurement at random times condition

\section{4) The performance of the blood glucose module}

The validation of the blood glucose value shown in the LCD was compared with the invasive blood glucose measurement. Based on Figure 6 and Figure 7, we can show the error 
and accuracy of blood glucose measurement with 2 conditions before eating and at random times were shown in Table 1 and Table 2, respectively.

Table 1. The Error and Accuracy of Blood Glucose Measurement with Before Eating Condition

\begin{tabular}{ccccc}
\hline Sample & $\begin{array}{c}\text { Blood Glucose } \\
\text { Non-Invasive } \\
\text { Module }(\mathrm{mg} / \mathrm{dl})\end{array}$ & $\begin{array}{c}\text { Easy Touch GCU } \\
(\mathrm{mg} / \mathrm{dL})\end{array}$ & Error $(\%)$ & Accuracy (\%) \\
\hline A & 78 & 79 & 1.30 & 98.70 \\
B & 90.3 & 96 & 5.90 & 94.10 \\
C & 81.6 & 79 & 3.30 & 96.70 \\
D & 136 & 149 & 8.72 & 91.28 \\
E & 61 & 58 & 5.17 & 94.83 \\
\hline
\end{tabular}

Table 2. The Error and Accuracy of Blood Glucose Measurement with Random Times Condition

\begin{tabular}{ccccc}
\hline Sample & $\begin{array}{c}\text { Blood Glucose } \\
\text { Non-Invasive } \\
\text { Module (mg/dl) }\end{array}$ & $\begin{array}{c}\text { Easy Touch GCU } \\
(\mathrm{mg} / \mathrm{dL})\end{array}$ & Error (\%) & Accuracy (\%) \\
\hline A & 134.6 & 143 & 5.87 & 94.13 \\
B & 134 & 147 & 8.84 & 91.16 \\
C & 61 & 58 & 5.17 & 94.83 \\
D & 82.3 & 81 & 1.60 & 98.40 \\
E & 121 & 123 & 1.62 & 98.38 \\
\hline
\end{tabular}

Non-invasive blood glucose was fully examined and tested in this study. Based on the measurement results that have been compared with comparative measuring instruments, it shows that this module can be used as a non-invasive self-monitoring of blood glucose. The output blood glucose values from measurements with non-invasive and invasive methods can be compared. The different results are seen, but this is still within the permitted tolerance limits. In principle, the non-invasive method, namely the light from the LED will penetrate the human skin and blood vessels, then the transmitted light is received by the photodiode sensor and its value is converted into blood glucose levels. So, the thickness of the finger will affect the intensity of light received by the sensor. It is recommended to use an LED at a wavelength of $940 \mathrm{~nm}$ with higher light intensity so that the absorption of blood glucose will be maximized and the light intensity that the sensor can accept will be higher.

Non-invasive blood glucose error measurement using the module showed a value of $1.04 \%$ with an accuracy of $98.40 \%$. The performance of the blood glucose module can show sensitivity and resolution of $0.86 \mathrm{mg} / \mathrm{dL}$ and $0.01 \mathrm{mg} / \mathrm{dL}$, respectively. This performance 
indicates that this non-invasive blood glucose measurement can be used as a self-monitoring of diabetes patients. The performance of this work was also compared to other works. Rghioui found that his Glucose Monitoring System has an accuracy of 99.17\% (13).

\section{CONCLUSION}

This study has exhibited the improvement of non-intrusive blood glucose estimation. This study was fabricated dependent on an Arduino microcontroller, some simple circuit, Super Bright Green LED as a transmitter and a photodiode sensor (BPW34) as a receiver. This study shows that accuracy can be used for monitoring of blood glucose. The error of blood glucose measurement using a module with a non-invasive method of $1.04 \%$ with an accuracy of $98.40 \%$. In the future, a non-invasive blood glucose measuring device designed in research can reduce medical waste and is more convenient to use.

\section{UCAPAN TERIMA KASIH}

DIPA Poltekkes Kemenkes Jakarta II Tahun 2020

\section{DAFTAR PUSTAKA}

1. Kementerian Kesehatan Republik Indonesia. Infodatin Data and Information Center Ministry of Health Republic of Indonesia (Mother's day). Pus Data dan Inf Kementeri Kesehat RI. 2014;1-6.

2. Roglic G, Unwin N, Bennett PH, Mathers C, Tuomilehto J, Nag S, et al. The burden of mortality attributable to diabetes: Realistic estimates for the year 2000. Diabetes Care. 2005;28(9):2130-5.

3. World Health Organization. a Vital Investment. World Health [Internet]. 2005;202. Available from:

http://scholar.google.com/scholar?hl=en\&btnG=Search\&q=intitle:Preventing+Chronic+Disea ses:+A+Vital+Investment\#3

4. Wild S, Roglic G, Green A, Sicree R, King H. Global prevalence of diabetes: estimates for the year 2000 and projections for 2030. Diabetes Care. 2004 May;27(5):1047-53.

5. Beckman J. Global E\&P "IDF DIABETES ATLAS.” Vol. 72, Offshore. 2012. 27 p.

6. Engelgau MM, Geiss LS, Saaddine JB, Boyle JP, Benjamin SM, Gregg EW, et al. The evolving diabetes burden in the United States. Ann Intern Med. 2004;140(11):945-50.

7. National Diabetes Factshee. a Preventive Diabetes Surveillance System," National Diabetes Factshee. 2003.

8. WHO. Diabetes: fakta dan angka. Epidemiol Situat [Internet]. 2015;2. Available from: https://www.who.int/leishmaniasis/burden/en/

9. Khairunnisa Z. Rancang Bangun Alat Ukur Kadar Gula Darah Non-Invasive Berbasis Sensor 
Fotodioda. Mipa IPB. 2014;1(1):1-30.

10. Zhang E, Xue C, Qiu J. Design and Human Trials of Microwave Noninvasive Blood Glucose Detection Sensor. 2018 IEEE Antennas Propag Soc Int Symp Usn Natl Radio Sci Meet APSURSI 2018 - Proc. 2018;0(c):1201-2.

11. Gayathri B, Sruthi K, Menon KAU. Non-invasive blood glucose monitoring using near infrared spectroscopy. In: 2017 International Conference on Communication and Signal Processing (ICCSP) [Internet]. IEEE; 2017. p. 1139-42. Available from: http://ieeexplore.ieee.org/document/8286555/

12. Asekar MS. Development of Portable Non-Invasive Blood Glucose Measuring Device Using NIR Spectroscopy. Proc 2nd Int Conf Intell Comput Control Syst ICICCS 2018. 2019;(Iciccs):572-5.

13. Rghioui A, Lloret J, Harane M, Oumnad A. A smart glucose monitoring system for diabetic patient. Electron. 2020;9(4):1-18. 